\title{
Special issue on design, test, integration and packaging of EMS/MOEMS, 2013
}

\author{
Bernard Courtois $^{1} \cdot$ Bernd Michel $^{2}$
}

Published online: 14 July 2015

(C) Springer-Verlag Berlin Heidelberg 2015

The Symposium on Design, Test, Integration and Packaging of MEMS/MOEMS (DTIP) was held in Aix-en-Provence, France, 11-13 May 2011, as a follow up to previous issues held in 1999 and 2000 in Paris, France, in 2001, 2002, 2003 in Mandelieu-La Napoule, France, in 2004 and 2005 in Montreux, Switzerland, and in 2006, 2007 in Stresa, Italy, in 2008 in Nice, France, in 2009 in Rome, Italy, in 2010 in Seville, Spain in 2011 in Aix-en-Provence, France and in Barcelona, Spain in 2013. This series of Symposia is a unique single-meeting event expressly planned to bring together participants interested in manufacturing microstructures and participants interested in design tools to facilitate the conception of these microstructures. The Symposium is traditionally composed of 2 conferences running in parallel: one on CAD, Design and Test (CDT), and another one on Microfabrication, Integration and Packaging (MIP). In addition, participants of both conferences can attend invited talks and special sessions.

This special issue is collecting reviewed and unabridged versions of papers presented at the Symposium. The papers have been again refereed, along the usual refereeing process in force at Microsystem Technologies. We are proud to offer these papers to the readers of this journal now.

Bernard Courtois

Bernard.Courtois@imag.fr

http://cmp.imag.fr

1 CMP, 46 avenue Felix Viallet, 38031 Grenoble Cedex, France

2 Micro Materials Center, Microsystem Technologies, Berlin, Germany
From 24 revised papers submitted to this special issue, 14 papers have been finally selected. They cover a broad range of topics. They appear successively in 9 categories.

There are: 1 paper on Assembly and Packaging, 1 on Characterization, 1 on Modeling and Characterization, 1 on RF MEMS, 1 on Sensors and 1 on In-Vitro Diagnostic Device, 2 papers on MEMS Accelerometers, 2 on Reliability Criteriain Mems/Nems Design, Manufacturing and Test, and finally 3 papers on Materials and Manufacturing.

We hope that you enjoy these contributions as much as we did.

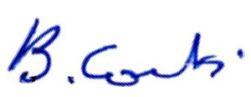

Bernard Courtois DTIP Chair and Guest Editor Microsystem Technologies<smiles>C=CC(C)C=C</smiles>

Bernd Michel Head of Micro Materials Center Editor-in-Chief, Microsystem Technologies 